Die Anfänge des Musikfeuilletons 
Ulrich Tadday

\section{Die Anfänge DeS Musikfeuilletons}

Der kommunikative Gebrauchswert musikalischer Bildung in Deutschland um 1800

Verlag J. B. Metzler

Stuttgart - Weimar 
Die Deutsche Bibliothek - CIP-Einheitsaufnahme

Tadday, Ulrich:

Die Anfänge des Musikfeuilletons : der kommunikative

Gebrauchswęrt musikalischer Bildung in Deutschland um 1800

/ Ulrich Tadday. - Stuttgart ; Weimar : 1993

ISBN 978-3-476-00933-3

ISBN 978-3-476-00933-3

ISBN 978-3-476-03484-7 (eBook)

DOI 10.1007/978-3-476-03484-7

Dieses Werk einschließlich aller seiner Teile ist urheberrechtlich geschützt.Jede Verwertung außerhalb der engen Grenzen des Urheberrechtsgesetzes ist ohne Zustimmung des Verlages unzulässig und strafbar. Das gilt insbesondere für Vervielfältigungen, Übersetzungen, Mikroverfilmungen und die Einspeicherung und Verarbeitung in elektronischen Systemen.

(C) 1993 Springer-Verlag GmbH Deutschland

Ursprünglich erschienen bei J. B. Metzlersche Verlagsbuchhandlung und Carl Ernst Poeschel Verlag GmbH in Stuttgart 1993 


\section{Vorwort}

Herrn Prof. Dr. Martin Geck danke ich für die Anregung und Betreuung dieser Arbeit, die im Namen der Universität Dortmund durch ein Graduiertenstipendium des Landes Nordrhein-Westfalen gefördert wurde.

Die Kosten für die Verfilmung relevanter Jahrgänge des Morgenblattes für gebildete Stände hat das Microfilmarchiv der deutschsprachigen Presse e. V. getragen. Herrn Prof. Dr. Hans Bohrmann gilt sowohl in seiner Funktion als Geschäftsführer des Microfilmarchivs der deutschsprachigen Presse e. V. als auch in seiner Funktion als Leiter des Instituts für Zeitungsforschung der Stadt Dortmund mein Dank. Des weiteren haben die Bayerische Staatsbibliothek, die Universitätsbibliothek München, die Universitätsbibliothek der Freien Universität Berlin sowie die Staatsbibliothek Preußischer Kulturbesitz ihre Handschriften und Bestände der Zeitung für die elegante Welt und des Freimüthigen oder Scherz und Ernst frei zur Verfügung gestellt. Dem CottaArchiv danke ich für Auskünfte und Unterstützung bei meinen Recherchen. Die auszugsweise Publikation einzelner Dokumente aus den Sammlungen der Handschriften-Abteilung des Schiller-Nationalmuseums und des Deutschen Literaturarchivs wurde genehmigt. 


\section{Inhaltsverzeichnis}

Vorwort $\quad$ V

$\begin{array}{ll}\text { Verzeichnis der Abkürzungen } & \text { IX }\end{array}$

$\begin{array}{ll}\text { Einleitung } & 1\end{array}$

1 Kritik der musikbezogenen Pressehistoriographie 3

2 Funktionale Aspekte des frühen Feuilletons $\quad 8$

2.1 Unterhaltung . . . . . . . . . . . . . . 9

2.2 Bildung ......................... 11

2.2.1 Bildung als Kompensationsmodell . . . . . . . . . 12

2.2.2 Bildung als Distinktionsmodell . . . . . . . . . . . 13

2.2.3 Bildung als Identitätsmodell . . . . . . . . . . . . 14

2.3 Kommunikation . . . . . . . . . . . . 16

2.4 Exkurs : Musikalische Bildung vor der Instanz der absoluten Musik . . . . . . . . . . . . . . 20

2.5 Der Tauschwert oder ökonomische Gebrauchswert der Bildung . . . . . . . . . . . . . . . . . 24

3 Zur Geschichte des Musikfeuilletons $\quad 28$

3.1 Zur Frage einer Definition ... . . . . . . . . . . . 28

3.2 Genealogie des Feuilletons ................ 33

3.2.1 Die Einflüsse der gelehrten Presse . . . . . . . . 34

3.2.2 Die Einflüsse der Unterhaltungspresse . . . . . . . 41

3.2.3 Der Einfluß der Tagespresse, Intelligenzblätter und Beilagen ................. 51

3.2.4 Exkurs: Die $A M Z$ als musikalische Fachzeitschrift . . . 63

4 Die feuilletonistischen Kulturzeitungen im Profil 68

4.1 Zeitung für die elegante Welt . . . . . . . . . . . 68

4.2 Der Freimüthige oder Scherz und Ernst . . . . . . . . . . . . . 74 
4.3 Morgenblatt für gebildete Stände . . . . . . . . . . . . 81

4.4 Bildungsbürgerliche Profile: Korrespondenten, Autoren und Redakteure . . . . . . . . . . . . . . . . 87

5 Kommunikationsstrukturen $\quad 106$

5.1 Themen, Beiträge und Formen . . . . . . . . . . 106

5.1.1 "Die Opern mögen an der Spitze stehen" . . . . . . . . 121

5.1.2 "Ein voller Concertsaal ist eine Seltenheit ..." . . . . . . 138

5.1.3 "Der wandernden Virtuosen ist Legion ..." . . . . . . . 146

5.1.4 "Ueber Musik und musikalische Instrumente unserer Zeit" . . . . . . . . . . . . . . 153

5.1.5 Musikleben: Instituts- und Vereinswesen . . . . . . 159

5.1.6 Ästhetik: "Musị als lebendiger Ausdruck und Seelenmalerei"? . . . . . . . . . . . . 166

5.1.7 "Sind unsre Volkslieder Naturoder Kunstprodukte?" . . . . . . . . . . . . 182

5.1.8 Musikbeilagen: "Das Konzert des häuslichen Lebens" . . . . . . . . . . . . . . . . 185

5.1.9 Musikalien: "... zur bildenden Uebung mit Recht zu empfehlen" . . . . . . . . . . . 205

5.2 Musikfeuilleton und AMZ im Jahr 1810: ein Vergleich . . . . . 208

6 Schluß

7 Literatur

8 Register

8.1 Hauptregister der Zeitung für die elegante Welt . . . . . . . . . 240

8.2 Hauptregister des Freimüthigen oder Scherz und Ernst . . . . . 282

8.3 Hauptregister des Morgenblatt für gebildete Stände . . . . . . . 315

8.4 Namensregister . . . . . . . . . . . . . . . 348

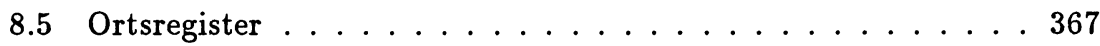




\section{Verzeichnis der Abkürzungen}

\begin{tabular}{|c|c|}
\hline $\mathrm{ADB}$ & Allgemeine Deutsche Biographie \\
\hline$A f M w$ & Archiv für Musikwissenschaft \\
\hline$A M Z$ & Allgemeine musikalische Zeitung \\
\hline$A Z$ & Allgemeine Zeitung \\
\hline BdT. & Bulletin der Tagesbegebenheiten \\
\hline$B M Z$ & Berliner Musikzeitung \\
\hline EDV & Elektronische Datenverarbeitung \\
\hline Fl. & Florin \\
\hline Fn & Fußnote \\
\hline$F r B$ & Der Freimüthige oder Scherz und Ernst \\
\hline i.e.S. & im engeren Sinn \\
\hline i.w.S. & im weiteren $\operatorname{Sin} n$ \\
\hline $\mathrm{kgl}$. & königlich \\
\hline $\mathrm{K}-\mathrm{N}$ & Korrespondenz-Nachrichten \\
\hline$M b l$ & Morgenblatt für gebildete Stände \\
\hline MGG & Musik in Geschichte und Gegenwart \\
\hline $\mathrm{NpZ}$. & Nicht politische Zeitung \\
\hline Rthlr. & Reichsthaler \\
\hline $\mathrm{T}$. & Tagesbegebenheiten \\
\hline UA & Uraufführung \\
\hline$W M$ & Westphälischer Moniteur \\
\hline ZeW & Zeitung für die elegante Welt \\
\hline
\end{tabular}

